\title{
Extracellular Cellobiose Lipid from Yeast and Their Analogues: Structures and Fungicidal Activities
}

\author{
Tatyana Kulakovskaya ${ }^{*}$, Alexander Shashkov², Ekaterina Kulakovskaya ${ }^{1}$, \\ Wladyslav Golubev ${ }^{1}$, Alexander Zinin ${ }^{2}$, Yury Tsvetkov², Alexey Grachev² and \\ Nikolay Nifantiev² \\ ${ }^{1}$ Skryabin Institute of Biochemistry and Physiology of Microorganisms, Russian Academy of Sciences (142290, Pushchino, pr. Nauki, 5, \\ Moscow Region, RUSSIA) \\ ${ }^{2}$ Zelinsky Institute of Organic Chemistry, Russian Academy of Sciences (119991, Moscow, Leninsky pr. RUSSIA)
}

\begin{abstract}
Basidiomycetous yeasts Cryptococcus humicola and Pseudozyma fusiformata secrete cellobiose lipids into the culture broth. In the case of $\mathrm{Cr}$. humicola, 16-(tetra-O-acetyl- $\beta$-cellobiosyloxy)-2hydroxyhexadecanoic acid was defined as major product and 16-(tetra-O-acetyl- $\beta$-cellobiosyloxy)-2,15dihydrohexadecanoic acid was defined as minor product, while Ps. fusiformata secreted mainly 16-[6-Oacetyl-2'-O-(3-hydroxyhexanoyl)- $\beta$-cellobiosyloxy)-2,15-dihydroxyhexadecanoic acid. These compounds exhibit similar fungicidal activities against different yeasts including pathogenic Cryptococcus and Candida species. The cells of Filobasidiella neoformans causing systemic cryptococcosis completely died after 30-min incubation with $0.02 \mathrm{mg} \mathrm{mL}^{-1}$ of cellobiose lipids. The same effect on ascomycetous yeast, including pathogenic Candida species, is achieved at $0.1-0.3 \mathrm{mg} \mathrm{mL}^{-1}$ of cellobiose lipids depending on the test culture used. Cellobiose lipid of Ps. fusiformata inhibits the growth of phytopathogenic fungi Sclerotinia sclerotiorum and Phomopsis helianthi more efficiently than cellobiose lipids from Cr. humicola. Fully $\mathrm{O}$ deacylated analogue, namely16-( $\beta$-cellobiosyloxy)-2-hydroxyhexadecanoic acid, and totally synthetic compound, 16-( $\beta$-cellobiosyloxy)-hexadecanoic acid, do not inhibit the growth of $F$. neoformans and Saccharomyces cerevisiae, while 16-( $\beta$-cellobiosyloxy)-2,15-dihydroxyhexadecanoic acid inhibits the growth of both test cultures but at higher concentrations than cellobiose lipids of $\mathrm{Cr}$. humicola and Ps. fusiformata . The amide of 16-( $\beta$-cellobiosyloxy)-2,15-dihydroxyhexadecanoic acid possessed no fungicide activity. Thus, the structures of both the carbohydrate part and fatty acid aglycon moiety are important for the fungicidal activity of cellobiose lipids.
\end{abstract}

Key words: cellobiose lipid, fungicide, biosurfactant, O-deacylated analogue, Cryptococcus humicola, Pseudozyma fusiformata, Filobasidiella neoformans, Candida albicans

\section{INTRODUCTION}

Some yeasts and mycelial fungi produce extracellular glycolipids ${ }^{1-3}$. These compounds contain carbohydrates in combination with fatty acids or hydroxy fatty acids. Glycolipids of various types, such as mannosylerythritols, sophorolipids, and cellobiose lipids, produced by Candida, Geotrichum, Kurtzmanomyces, Pseudozyma, and Ustilago species are believed to act as biosurfactants and facilitate dissolution of organic hydrophobic compounds and their consumption by microbial cells ${ }^{2-4}$. Multiple biological activities and potential applications of extracellular yeast glycolipids in the food industry, bioremediation, pharmaceutics and medicine are discussed in reviews ${ }^{2,3,5-7)}$.

Cellobiose lipids have been known as extracellular products of Ustilago maydis for a long time ${ }^{8-10}$. However, their functions and biological activities were still obscure and the observed antibiotic activity was low ${ }^{9}$. Recently it was shown that cellobiose lipids of Pseudozyma fusiformata

* Correspondence to: Tatyana Kulakovskaya, Skryabin Institute of Biochemistry and Physiology of Microorganisms, Russian Academy of Sciences, 142290, Pushchino, pr. Nauki, 5, Moscow Region, RUSSIA

E-mail: alla@ibpm.pushchino.ru

Accepted November 11, 2008 (received for review September 29, 2008)

Journal of Oleo Science ISSN 1345-8957 print / ISSN 1347-3352 online

http://www.jstage.jst.go.jp/browse/jos/ 
T. Kulakovskaya, A. Shashkov, E. Kulakovskaya et al.

and Cryptococcus humicola exhibit fungicide activities against many species of yeast and mycelial fungi ${ }^{11-13}$. In the case of $\mathrm{Cr}$. humicola, 16 -(tetra-O-acetyl- $\beta$-cellobiosyloxy)2 -hydroxyhexadecanoic acid was defined as a major product $^{12)}$ while $P$ s. fusiformata secrete 16-[6-O-acetyl-2'-O-(3hydroxyhexanoyl)- $\beta$-cellobiosyloxy)-2,15-dihydroxyhexadecanoic acid ${ }^{13)}$ (Fig. 1). Pseudozyma flocculosa cellobiose lipid possesses $\mathrm{C}_{8}$-hydroxy acid and two acetyl groups in the cellobiose residue and exhibit also fungicidal activity ${ }^{14,15}$. The broad spectra of activity, $\mathrm{pH}$ and temperature stability allow one to consider cellobiose lipids as promising natural biocontrol agents of pathogenic yeast and mycelial fungi and to use them in feed and food preservation from fungal spoilage.

The known antifungal cellobiose lipids produced by yeasts differ in their structures. The goal of our study was to assess the structural features of cellobiose lipids, which determine their fungicidal activity.
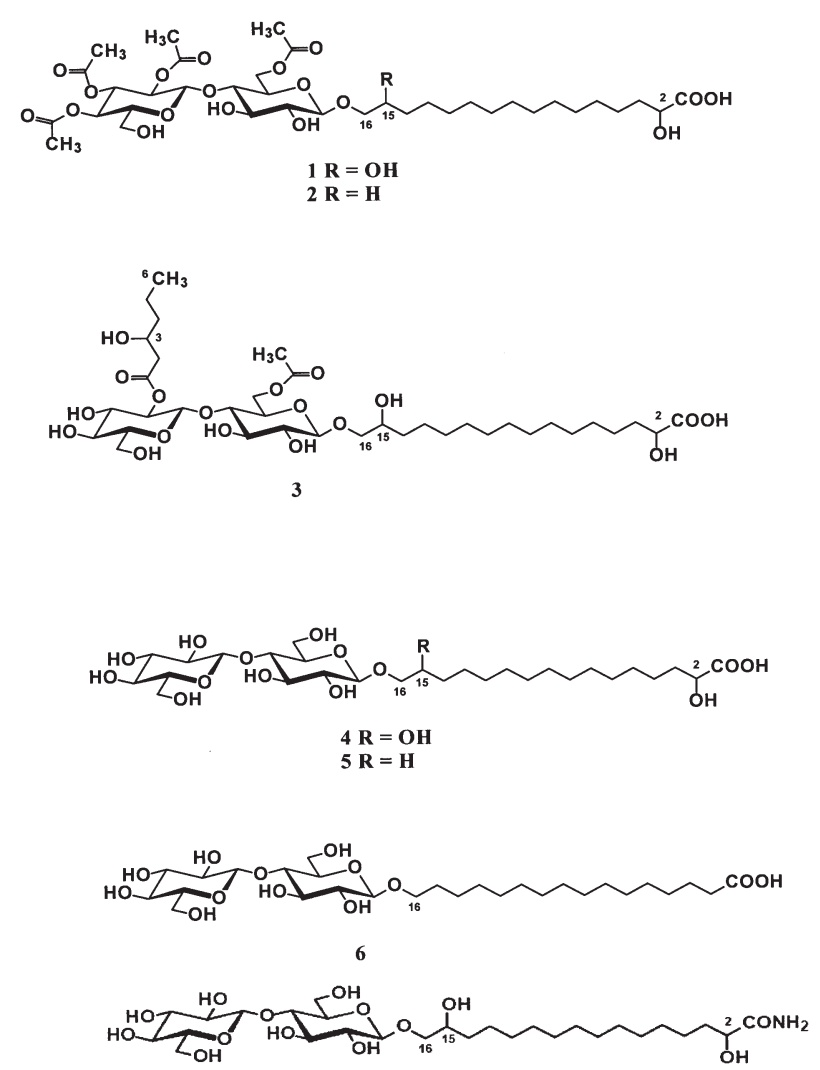

7

Fig. 1 The Structures of Cellobiose Lipids from Culture Broth of Cryptococcus humicola (1-2),Pseudozyma fusiformata (3), Deacylated Derivativies of Glycolipids 1-2 (4,5), Synthetic Compound 16-( $\beta$ Cellobiosyloxy)-Hexadecanoic Acid (6) and Acetamide of Glycolipid 4 (7).

\section{EXPERIMENTAL}

\subsection{Strains and growth conditions}

Yeasts Cr. humicola 9-6 and Ps. fusiformata VKM Y2821 producing glycolipids were obtained from the Russian Collection of Microorganisms (VKM, http://www.vkm.ru) and grown in a liquid medium as described earlier ${ }^{16,17)}$. Yeast strains Cryptococcus terreus VKM Y-2253, Saccharomyces cerevisiae VKM Y-1173, Candida albicans JCM 1542 (Japanese Collection of Microorganisms), Filobasidiella neoformans IGC 3957, Clavispora lusitaniae IGC 2705 (Gulbekyan Institute Collection, Portugal), Candida glabrata CBS 138, Candida viswanathii CBS 4024 (Central Collection of Pure Fungi Cultures, Netherlands), fungus Mucor mucedo VKM F-1355 (Russian Collection of Microorganisms) and phytopathogenic fungi Phomopsis helianthi and Sclerotinia sclerotiorum from laboratory collection were used as test cultures. The cultures were grown in the media described earlier $1^{6,17}$.

\subsection{Cellobiose lipids purification}

Cellobiose lipids were purified from culture broth after separation from biomass ${ }^{16,17}$. The concentrations of glycolipids were determined by weighing after methanol evaporation.

\subsection{Preparation of 2,15-dihydroxy- and 15-hydroxy-16-[4-O-} ( $\boldsymbol{\beta}$-D-glucopyranosyl)- $\boldsymbol{\beta}$-D-glucopyranosyloxy)hexadecanoic acids (4 and 5 , Fig. 1 )

A purified glycolipid preparation of $C r$. humicola was evaporated to dryness under vacuum to yield $64 \mathrm{mg}$ of compounds, which were then dissolved in absolute methanol $(2 \mathrm{~mL})$ under argon. A solution of $\mathrm{KOH}(2 \mathrm{mmol})$ in absolute methanol $(3 \mathrm{~mL})$ was then added with stirring, and the mixture was agitated for $14 \mathrm{~h}$ at $20^{\circ} \mathrm{C}$. Then it was cooled to $-40^{\circ} \mathrm{C}$; acetyl chloride $(0.67 \mathrm{~mL})$ was added dropwise with stirring, the mixture was allowed to warm to $20^{\circ} \mathrm{C}$, and stirring was continued at this temperature for 8 $\mathrm{h}$. The volatiles were then removed under vacuum, the residue was dissolved in a mixture of pyridine $(2 \mathrm{~mL})$ and acetic anhydride $(2 \mathrm{~mL})$, and the solution was let stand for 1 day at $20^{\circ} \mathrm{C}$. Methanol $(2 \mathrm{~mL})$ was added with cooling in an ice-water bath, so that the temperature would not rise above $40^{\circ} \mathrm{C}$. After standing for $0.5 \mathrm{~h}$ at $20^{\circ} \mathrm{C}$, the mixture was evaporated to dryness. Toluene $(4 \times 5 \mathrm{~mL})$ was distilled from the residue under reduced pressure. The residue was dissolved in $\mathrm{CHCl}_{3}(20 \mathrm{~mL})$, filtered through a Celite pad, and evaporated again. The mixture of peracetylated methyl esters of glycolipids 8 and 9 thus formed was separated by column chromatography on silica gel (gradient elution: benzene $\rightarrow$ benzene - EtOAc $1: 1 \mathrm{v} / \mathrm{v}$, then benzene - EtOAc 1:1) to yield individual compounds $8(10 \mathrm{mg})$ and 9 (32 mg). Products 8 and 9 (Fig. 2) were subjected to saponification to produce glycolipids 4 and 5 as described below for preparing compound 6 . Triethylammonium salts 


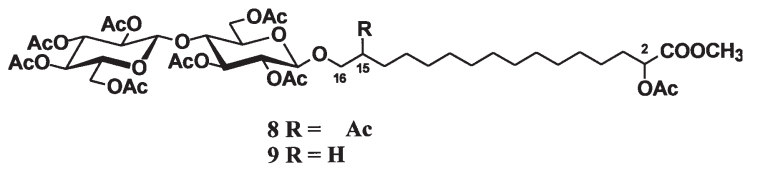

Fig. 2 The Structure of Cellobiose Lipid $\mathbf{8}$ and $\mathbf{9}$.

of $4(7 \mathrm{mg})$ and $5(21 \mathrm{mg})$ were obtained by neutralization with triethylamine. Their structures were confirmed by ${ }^{1} \mathrm{H}$ and ${ }^{13} \mathrm{C}$ NMR spectroscopy (Table 1). ESI-MS (-) data for compound 5: calculated for [M-H] $]^{-}$611.3; found 611.6.
2.4 Preparation of 2,15-dihydroxy-16-[4-O-( $\beta$-D-glucopyranosyl)- $\boldsymbol{\beta}$-D-glucopyranosyloxy) hexadecanoic acids acetamide (7, Fig. 1)

A solution of glycolipid of Ps. fusiformata was evaporated under reduced pressure. The residue (395 mg) was partitioned between water-saturated $n$-butanol $(10 \mathrm{~mL})$ and water $(10 \mathrm{~mL})$, and the aqueous phase was extracted 3 times $(10 \mathrm{~mL}$, then $2 \times 5 \mathrm{~mL})$ with water-saturated $n$ butanol. The combined organic phases were evaporated under reduced pressure. The residue (176 mg) was dissolved in methanol $(20 \mathrm{~mL})$ under argon; powdered $\mathrm{KOH}$ (300 mg) was added, and the mixture was stirred at $\mathrm{rt}$ for $16 \mathrm{~h}$. The solvent was evaporated; water $(10 \mathrm{~mL})$ was added

Table $1 \quad{ }^{1} \mathrm{H}$ and ${ }^{13} \mathrm{C}$ NMR Spectral data of Glycolipids in $\mathrm{CD}_{3} \mathrm{OD}$.

\begin{tabular}{|c|c|c|c|c|c|c|c|c|c|c|c|}
\hline \multirow{2}{*}{$\begin{array}{c}\text { Structural } \\
\text { Unit }\end{array}$} & \multirow{2}{*}{$\begin{array}{l}\mathrm{J}_{1,2} \text { or } \\
\text { proton } \\
\text { number }\end{array}$} & \multicolumn{5}{|c|}{${ }^{1} \mathrm{H}$ NMR shifts $(\delta$, ppm$)$ and $\mathrm{J}_{1,2}(\mathrm{~Hz})$} & \multirow{2}{*}{$\begin{array}{l}\text { Carbon } \\
\text { number }\end{array}$} & \multicolumn{4}{|c|}{${ }^{13} \mathrm{C}$ NMR shifts; $\delta$, ppm } \\
\hline & & 4 & 5 & $6^{* *}$ & 7 & $11 * * *$ & & 4 & 5 & $6^{* *}$ & 7 \\
\hline \multirow{8}{*}{$\beta$-D-Glc- $(1 \rightarrow$} & $J 1,2$ & 7.8 & 7.9 & 7.8 & 7.9 & n.d. & $C-1$ & 104.7 & 104.6 & 105.0 & 104.6 \\
\hline & $H-1$ & 4.41 & 4.41 & 5.17 & 4.42 & 4.48 & $C-2$ & 75.0 & 74.9 & 74.9 & 74.9 \\
\hline & $H-2$ & 3.23 & 3.22 & 4.08 & 3.23 & 4.89 & $C-3$ & 77.9 & 77.9 & 78.2 & 77.9 \\
\hline & $H-3$ & 3.37 & 3.37 & 4.19 & 3.37 & 5.11 & $C-4$ & 71.4 & 71.4 & 71.6 & 71.4 \\
\hline & $H-4$ & 3.31 & 3.31 & 4.17 & 3.30 & 5.03 & $C-5$ & 78.1 & 78.1 & 78.4 & 78.1 \\
\hline & $H-5$ & 3.33 & 3.34 & 4.0 & 3.33 & 3.63 & $C-6$ & 62.4 & 62.5 & 62.5 & 62.4 \\
\hline & $H-6$ & 3.88 & 3.87 & 4.52 & 3.88 & 4.34 & & & & & \\
\hline & $H-6^{\prime}$ & 3.66 & 3.65 & 4.28 & 3.66 & 4.02 & & & & & \\
\hline \multirow{8}{*}{$\rightarrow 4)-\beta$-D-Glc- $(1 \rightarrow$} & $J 1,2$ & 7.8 & 7.9 & 7.8 & 7.8 & 7.9 & $C-1$ & 104.7 & 104.2 & 105.2 & 104.2 \\
\hline & $H-1$ & 4.31 & 4.27 & 4.92 & 4.27 & 4.42 & $C-2$ & 75.0 & 74.9 & 74.8 & 74.9 \\
\hline & $H-2$ & 3.28 & 3.23 & 4.05 & 3.23 & 4.86 & $C-3$ & 76.2 & 76.4 & 76.8 & 76.5 \\
\hline & $H-3$ & 3.52 & 3.51 & 4.25 & 3.51 & 5.15 & $C-4$ & 80.7 & 80.8 & 81.3 & 80.8 \\
\hline & $H-4$ & 3.57 & 3.56 & 4.31 & 3.56 & 3.73 & $C-5$ & 76.5 & 76.4 & 76.6 & 76.5 \\
\hline & $H-5$ & 3.41 & 3.39 & 3.9 & 3.39 & 3.55 & $C-6$ & 61.8 & 61.9 & 62.1 & 61.9 \\
\hline & $H-6$ & 3.88 & 3.86 & 4.53 & 3.88 & 4.47 & & & & & \\
\hline & $H-6^{\prime}$ & 3.88 & 3.86 & 4.48 & 3.88 & 4.06 & & & & & \\
\hline \multirow{12}{*}{ Aglycon } & $H-2$ & 3.87 & 3.87 & 4.58 & 2.15 & 2.28 & $C-1$ & 181.6 & 181.6 & 178.4 & 182.7 \\
\hline & $H-3$ & 1.74 & 1.73 & 2.21 & 1.59 & 1.60 & $C-2$ & 73.5 & 73.5 & 72.4 & 39.1 \\
\hline & $H-3^{\prime}$ & 1.57 & 1.55 & 2.05 & 1.59 & 1.60 & $C-3$ & 36.2 & 36.2 & 35.7 & 27.7 \\
\hline & $H-4$ & 1.43 & 1.39 & 1.75 & 1.31 & $*$ & $C-4$ & 26.4 & 26.4 & 25.8 & 30.6 \\
\hline & $H-5$ & $*$ & 1.32 & 1.35 & $*$ & $*$ & $C-5-C-12$ & 30.7 & 30.7 & 29.9 & 30.6 \\
\hline & $H-6-H-12$ & $1.30-1.32$ & $1.29-1.31$ & $1.21-1.29$ & $1.28-1.30$ & $1.22-1.28$ & $C-13$ & 26.6 & 30.7 & 26.1 & 30.6 \\
\hline & $H-13$ & 1.35 & $*$ & 1.65 & $*$ & $*$ & $C-14$ & 34.3 & 27.1 & 34.3 & 27.1 \\
\hline & $H-13^{\prime}$ & 1.35 & $*$ & 1.48 & $*$ & $*$ & $C-15$ & 71.7 & 30.7 & 70.7 & 30.7 \\
\hline & $H-14$ & 1.43 & 1.38 & 1.65 & 1.38 & * & $C-16$ & 75.7 & 71.0 & 75.9 & 70.9 \\
\hline & $H-15$ & 3.76 & 1.62 & 4.14 & 1.61 & 1.52 & & & & & \\
\hline & $H-16$ & 3.89 & 3.87 & 4.19 & 3.87 & 3.80 & & & & & \\
\hline & $H-16^{\prime}$ & 3.38 & 3.53 & 3.84 & 3.54 & 3.42 & & & & & \\
\hline \multirow{2}{*}{$\mathrm{Et}_{3} \mathrm{NH}^{+}$} & $\mathrm{CH} 2$ & 2.89 & 2.96 & - & 2.97 & - & $\mathrm{CH} 2$ & 47.4 & 47.5 & - & 47.4 \\
\hline & $\mathrm{CH} 3$ & 1.19 & 1.21 & - & 1.21 & - & $\mathrm{CH} 3$ & 10.1 & 9.9 & - & 9.8 \\
\hline
\end{tabular}

* This signal is located in the same area with H-6 - H-12 signals.

** Spectrum was recorded in $\mathrm{C}_{5} \mathrm{D}_{5} \mathrm{~N}$, signal of $\mathrm{NH}_{2}$ group is at $\delta 8,07 \mathrm{ppm}$.

*** Spectrum was recorded in $\mathrm{CDCl}_{3}$, signal of $\mathrm{OCH}_{3}$ group is at $\delta 3,64 \mathrm{ppm}$. 


\section{T. Kulakovskaya, A. Shashkov, E. Kulakovskaya et al.}

to the residue, the mixture was acidified with acetic acid $(0.4 \mathrm{~mL})$, and the resulting suspension was extracted 3 times with $\mathrm{Et}_{2} \mathrm{O}(10 \mathrm{~mL}$, then $2 \times 5 \mathrm{~mL})$ to remove non-carbohydrate lipids. Evaporation of the ethereal extracts gave $29 \mathrm{mg}$ of a lipid fraction.

The saponified glycolipid was extracted from the remaining aqueous suspension with water-saturated $n$ butanol $(10 \mathrm{~mL}$, then $3 \times 5 \mathrm{~mL})$. The extracts were evaporated under reduced pressure; the residue (containing an admixture of $\mathrm{AcOK}$ ) was once more suspended in water (10 $\mathrm{mL}$ ) and extracted with water-saturated $n$-butanol in a similar manner. After evaporation of the solvent, the residue was dried in vacuum of an oil pump to give an amorphous solid (76 mg).

The saponified glycolipid thus obtained was suspended in absolute methanol $(10 \mathrm{~mL})$ under argon. To the cooled $\left(-20^{\circ} \mathrm{C}\right)$ and stirred suspension was added acetyl chloride $\mathrm{AcCl}(0.5 \mathrm{~mL})$ dropwise. The mixture was allowed to warm to room temperature and the stirring was continued for 16 $h$. Then the volatiles were removed under reduced pressure, and the residue was dissolved in absolute pyridine (2 $\mathrm{mL})$. Acetic anhydride $(2 \mathrm{~mL})$ was added, and the mixture was allowed to stand at room temperature for $20 \mathrm{~h}$. Methanol $(2 \mathrm{~mL})$ was then added with stirring and cooling, the mixture was left for $30 \mathrm{~min}$, and the volatiles were removed under reduced pressure. Toluene $(5 \times 5 \mathrm{~mL})$ was distilled under reduced pressure from the residue. Subsequent column chromatography of the resulting mixture $(128 \mathrm{mg}$ ) on silica gel (gradient elution: benzene $\rightarrow$ benzene ethyl acetate $1: 1 \mathrm{v} / \mathrm{v}$, then benzene-ethyl acetate 1:1) provided peracetylated methyl ester of glycolipid of $P s$. fusiformata (74 mg).

Peracetylated methyl ester of glycolipid $(43 \mathrm{mg})$ was dissolved in absolute methanol $(1 \mathrm{~mL})$; ammonia-saturated absolute methanol $(4 \mathrm{~mL})$ was added, and the mixture was allowed to stand at room temperature for $66 \mathrm{~h}$ (TLC showed the completion of the reaction). The volatiles were evaporated under reduced pressure and acetamide formed was removed by sublimation in vacuum of an oil pump at $50^{\circ} \mathrm{C}$ to provide $27 \mathrm{mg}$ of amide of glycolipid, which was pure according TLC and NMR.

\subsection{Preparation of 16 -[4-O-( $\beta$-D-glucopyranosyl)- $\beta$-D-glu- copyranosyloxy)] hexadecanoic acid (6, Fig. 1)}

Powdered molecular sieves $4 \AA$ (100 mg) was added to a solution of 4-O-(2,3,4,6-tetra-O-acetyl- $\beta$-D-glucopyranosyl)2,3,6-tri-O-acetyl- $\beta$-D-glucopyranosyl trichloroacetimidate $10^{19)}(80.6 \mathrm{mg}, 0.103 \mathrm{mmol}$ ) and methyl 16-hydroxyhexadecanoate $(11)^{20)}\left(36.7 \mathrm{mg}, 0.128 \mathrm{mmol}\right.$,) in dry $\mathrm{CH}_{2} \mathrm{Cl}_{2}(1.5 \mathrm{~mL})$ under argon, and the mixture was agitated at $20^{\circ} \mathrm{C}$ for $1 \mathrm{~h}$. After cooling to $0^{\circ} \mathrm{C}$, a $0.08 \mathrm{M}$ solution of trimethylsilyl trifluoromethanesulfonate (TMSOTf) in $\mathrm{CH}_{2} \mathrm{Cl}_{2}(0.1 \mathrm{~mL})$ was added dropwise with stirring. More TMSOTf solution was added after $15 \mathrm{~min}, 60 \mathrm{~min}, 80 \mathrm{~min}$, and $2 \mathrm{~h}(0.12 \mathrm{~mL}, 0.5$

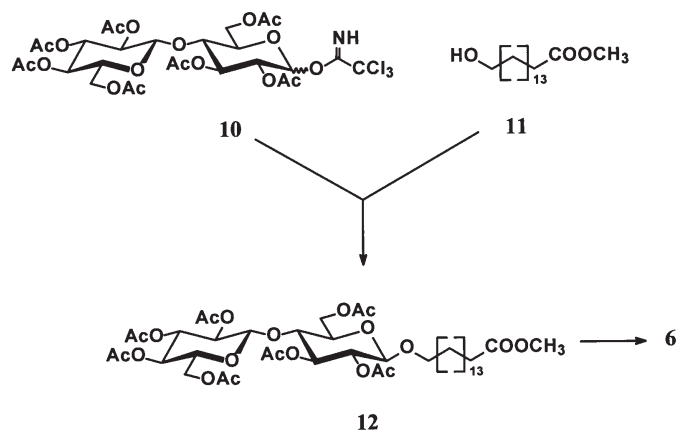

Fig. 3 The Intermediate Compounds for Obtaining of 16[4-O-( $\beta$-D-Glucopyranosyl)- $\beta$-D-Glucopyranosyloxy)] Hexadecanoic Acid (6).

$\mathrm{mL}, 0.75 \mathrm{~mL}$, and $0.9 \mathrm{~mL}$, respectively). The cooling bath was then removed, and the mixture was stirred for $2 \mathrm{~h}$ at $20^{\circ} \mathrm{C}$. The reaction was quenched with triethylamine $(0.2$ $\mathrm{mL}$ ); the mixture was diluted with benzene, filtered through a Celite pad, and the solvent was removed under vacuum. Column chromatography of the residue (silica gel, gradient elution $10 \rightarrow 45 \%$ EtOAc/benzene) gave methyl 16-[4-O-(2,3,4,6-tetra-O-acetyl- $\beta$-D-glucopyranosyl)-2,3,6tri-O-acetyl- $\beta$-D-glucopyranosyloxy]hexadecanoate $(11,24$ $\mathrm{mg}, 26 \%)$ as a white foam. The solution of $\mathrm{KOH}(82 \mathrm{mg})$ in methanol $(2 \mathrm{~mL})$ was added to the solution of product 12 (47 mg, $52 \mathrm{umol}$ ) in methanol $(2 \mathrm{~mL})$ under argon, and the mixture was stirred for $1 \mathrm{~h}$ at room temperature. The resulting mixture was diluted with water $(4 \mathrm{~mL})$, and stirring was continued for $16 \mathrm{~h}$ at room temperature. Then the mixture was evaporated to dryness in vacuum. The residue was suspended in water $(5 \mathrm{~mL})$, acidified with $\mathrm{AcOH}(0.08$ $\mathrm{mL})$, and extracted with water-saturated $n$-butanol $(9 \mathrm{~mL}$ and then $2 \times 1 \mathrm{~mL}$ ). The extracts were combined and evaporated to dryness, and the residue (31 $\mathrm{mg}$, quant.) was crystallized from methanol - i-PrOH - MeCN to give glycolipid $6(27 \mathrm{mg}, 87 \%)$ as fine white needles. Its structure was confirmed by ${ }^{1} \mathrm{H}$ NMR spectroscopy (Table 1). ESI-MS (-) data for compound 6: calculated for $[\mathrm{M}-\mathrm{H}]^{-}$595.3; found 595.9. Figure 3 shows the structures of intermediate compounds for the preparation of compound 6 .

\subsection{NMR spectroscopy and ESI-MS analysis}

One-dimensional ${ }^{1} \mathrm{H}-\mathrm{NMR},{ }^{13} \mathrm{C}-\mathrm{NMR}$, two-dimensional ${ }^{1} \mathrm{H},{ }^{1} \mathrm{H}$ COSY, TOCSY, ROESY, ${ }^{1} \mathrm{H},{ }^{13} \mathrm{C}$ HSQC and HMBC spectra were recorded with a Bruker DRX-500 spectrometer (Germany) at $30^{\circ} \mathrm{C}$. The sample was examined in pyridine-d5 with TMS as an internal standard. 2D spectra were obtained using standard pulse sequences from the Bruker software. The mixing time of 200 and $100 \mathrm{~ms}$ was used in 2D TOCSY and ROESY experiments, respectively. The HMBC experiment was optimized for coupling constant $\mathrm{J}_{\mathrm{H}, \mathrm{C}} 5 \mathrm{~Hz}$. The glycolipids 5 and 6 were analyzed by electro- 
spray mass spectrometry (ESI-MS) in the negative mode using a LCO DECAXP mass spectrometer (Thermo Finnigan, USA).

\subsection{Fungicidal activity assay}

Cell viability of the test cultures was determined by cultivation on agar medium after incubation with glycolipids in $40 \mathrm{mM}$ citrate-phosphate buffer, $\mathrm{pH}$ 4.0, at room temperature for $30 \mathrm{~min}^{13)}$. The inhibition of growth of the test cultures was also assayed in Petri dishes with glucose-peptone agar containing the same buffer, $\mathrm{pH}$ 4.0. Glass fiber disks GF/A (Whatman), $5 \mathrm{~mm}$ in diameter, containing different amounts of glycolipids were placed onto the surface of medium inoculated with the test cultures. All data in the tables are average values of three experiments with standard deviation no more than 5-10\%.

\section{RESULTS AND DISCUSSION}

The cellobiose lipids secreted by the yeasts $C r$. humico$l a$ and Ps. fusiformata differ in their structures as was determined by NMR-spectroscopy (Table 1) and massspectrometry. Figure 1 shows the structures of cellobiose lipids used in this study. In the case of $\mathrm{Cr}$. humicola, 16(tetra-O-acetyl- $\beta$-cellobiosyloxy)-2-hydroxyhexadecanoic acid (2) and 16-(tetra-O-acetyl- $\beta$-cellobiosyloxy)-2,15-dihydroxyhexadecanoic acid (1) were defined as a major and minor products, respectively. Ps. fusiformata secreted mainly 16-[6-O-acetyl-2'-O-(3-hydroxyhexanoyl)- $\beta$-cellobiosyloxy)-2,15-dihydroxyhexadecanoic acid (3). It was in the agreement with the data obtained earlier ${ }^{12,13)}$.

The cellobiose lipid preparations obtained from the culture broth of $\mathrm{Cr}$. humicola and Ps. fusiformata demonstrated growth inhibition activities against different yeast species. For example, Fig. 4 shows growth inhibition zones under cultivation of test cultures on a solid medium in the presence of different aliquots of cellobiose lipid (3) secreted by Ps. fusiformata.

The glycolipid preparation of Cr. humicola and compound (3) have almost identical fungicidal activities against yeast species under study (Tables 2, 3). Both cellobiose lipids inhibit the growth of a number of species important for medicine: C. albicans, C. glabrata, C. viswanathii, $F$. neoformans and $\mathrm{Cl}$. lusitaniae. Cellobiose lipids were more efficient against basidiomycetous yeasts of the genera Cryptococcus and Filobasidiella than against ascomycetous yeasts of the genera Saccharomyces, Candida and Clavispora.

The growth of mycelial fungi under study was more efficiently inhibited by cellobiose lipid (3) (Table 2, Fig. 5). The amount of glycolipid (3) giving growth inhibition zones of 10-20 mm for phytopathogenic fungus Sclerotinia sclerotiorum were 2.5 times lower than that of $\mathrm{Cr}$. humicola cel-

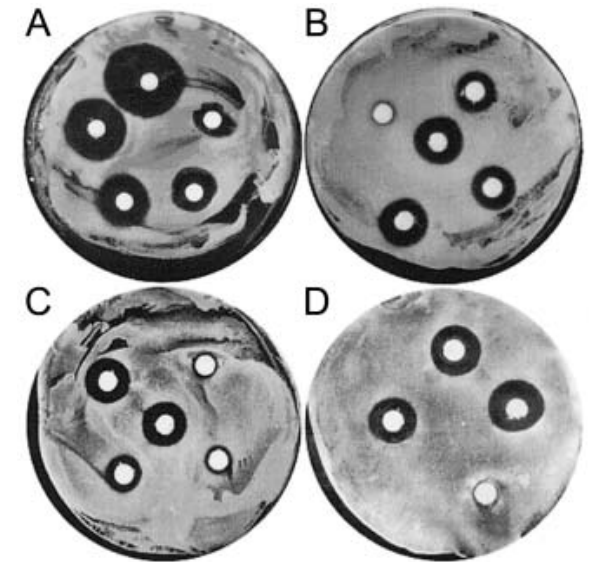

Fig. 4 The Inhibition of Yeast Growth by Cellobiose Lipid (3) of Pseudozyma fusiformata.

Test cultures: A - Cryptococcus terreus VKM Y$2253(0.01,0.02,0.03,0.06,0.12), \mathrm{B}-$ Filobasidiella neoformans IGC 3957 (0.01, 0.02, 0.03, 0.04, 0.06), C - Candida albicans JCM 1542 (0.03, 0.06, 0.12, 0.2, 0.3), and D - Saccharomyces cerevisiae BKM Y-1173 (0.06, 0.12, 0.2, 0.3). Glucose-peptone agar containing $0.04 \mathrm{M}$ citratephosphate buffer, $\mathrm{pH} 4.0$ was used as a solid medium. The amounts of glycolipid (mg per disc) placed on Whatman GF A glass fiber discs are indicated in brackets.
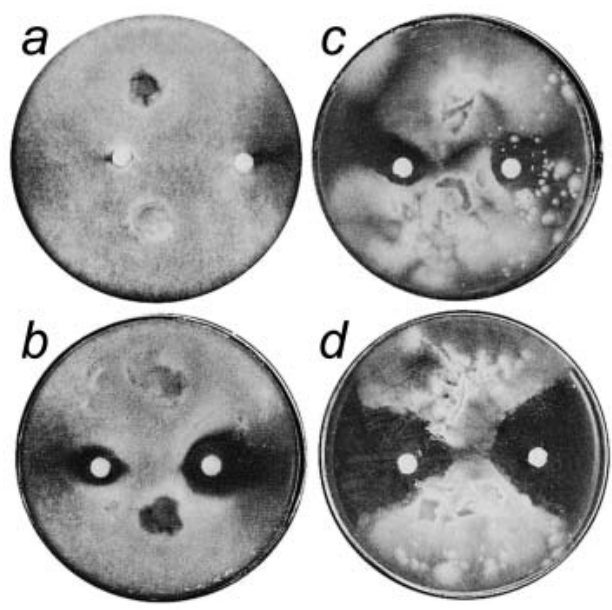

Fig.5 The Inhibition of Fungi Growth by Cellobiose Lipids.

a - Sclerotinia sclerotiorum, cellobiose lipid of Cryptococcus humicola ( 0.2 and $0.5 \mathrm{mg}$ per disc); b

- Sc. sclerotiorum, cellobiose lipid of Pseudozyma fusiformata (0.2 and $0.5 \mathrm{mg}$ per disc); c - Mucor mucedo VKM F-1355, cellobiose lipid of Cryptococcus humicola ( 0.2 and $0.5 \mathrm{mg}$ per disc); $\mathrm{d}$ - M. mucedo VKM F-1355, cellobiose lipid of Pseudozyma fusiformata (0.1 and $0.3 \mathrm{mg}$ per disc) 
T. Kulakovskaya, A. Shashkov, E. Kulakovskaya et al.

Table 2 The Amount of Cellobiose Lipids of Cr. humicola and Ps. fusiformata Giving 15-20 mm Zones of Growth Inhibition at pH 4.0.

\begin{tabular}{lcc}
\hline \multicolumn{1}{c}{ Test culture } & \multicolumn{2}{c}{ Glycolipid amount, mg } \\
& Cellobiose lipid of & Cellobiose lipid of \\
Cr. humicola 9-6 & Ps. Fusiformata \\
Filobasidiella neoformans & 0.05 & 0.02 \\
Clavispora lusitaniae & 0.05 & 0.02 \\
Saccharomyces cerevisiae & 0.3 & 0.2 \\
Candida albicans & 0.3 & 0.2 \\
Candida glabrata & 0.3 & 0.2 \\
Candida viswanathii & 0.3 & 0.2 \\
Sclerotinia sclerotiorum & 0.2 & 0.1 \\
Phomopsis helianthi & 0.5 & 0.1 \\
Mucor mucedo & - & 0.1 \\
\hline
\end{tabular}

Table 3 The Concentrations of Cellobiose Lipids of Cr. humicola and Ps. fusiformata Causing Almost Complete Death of the Cells of Test Cultures after 30-min Incubation.

\begin{tabular}{lcc}
\hline \multicolumn{1}{c}{ Test culture } & \multicolumn{2}{c}{ Concentration, $\mathrm{mg} / \mathrm{ml}$} \\
& $\begin{array}{c}\text { Cellobiose lipid of } \\
\text { Cr. humicola }\end{array}$ & $\begin{array}{c}\text { Cellobiose lipid of } \\
\text { Ps. fusiformata }\end{array}$ \\
Cryptococcus terreus & 0.02 & 0.02 \\
Filobasidiella neoformans & 0.02 & 0.02 \\
Clavispora lusitaniae & 0.15 & 0.1 \\
Candida viswanathii & 0.15 & 0.1 \\
Candida albicans & 0.15 & 0.15 \\
Candida glabrata & 0.3 & 0.3 \\
Saccharomyces cerevisiae & 0.3 & 0.3 \\
\hline
\end{tabular}

Table 4 Diameters of Growth Inhibition Zones ( $\mathrm{mm}$ ) under the Action of Natural and Synthetic Cellobiose Lipids and Their Derivates.

\begin{tabular}{|c|c|c|c|}
\hline \multirow{2}{*}{$\begin{array}{c}\text { Cellobiose lipids } \\
\text { (Fig. 1) }\end{array}$} & $\begin{array}{c}\mid 3 \\
\text { Saccharomyces } \\
\text { cerevisiae }\end{array}$ & $\begin{array}{c}\text { Cryptococcus } \\
\text { terreus }\end{array}$ & $\begin{array}{c}\text { Filobasidiella } \\
\text { neoformans }\end{array}$ \\
\hline $\begin{array}{c}\text { Cellobiose lipid of } \\
\text { Cr. humicola }\end{array}$ & $5(0.2 \mathrm{mg})$ & $5(0.01 \mathrm{mg})$ & $5(0.01 \mathrm{mg})$ \\
\hline$(4)$ & $5(0.7 \mathrm{mg})$ & $5(0.7 \mathrm{mg})$ & $5(0.7 \mathrm{mg})$ \\
\hline$(\mathbf{5})$ & $0(0.8 \mathrm{mg})$ & $0(0.8 \mathrm{mg})$ & $0(0.8 \mathrm{mg})$ \\
\hline$(6)$ & $0(1 \mathrm{mg})$ & $0(1 \mathrm{mg})$ & $0(1 \mathrm{mg})$ \\
\hline$(7)$ & $0(1 \mathrm{mg})$ & $0(1 \mathrm{mg})$ & $0(1 \mathrm{mg})$ \\
\hline
\end{tabular}

The amounts of glycolipids per disc are given in brackets 
lobiose lipids. Ph. helianthii and Mucor mucedo were less sensitive to the glycolipid from $\mathrm{Cr}$. humicola. Even at application of $0.5 \mathrm{mg}$ of this compound onto the disk, the diameters of growth inhibition zones were no more than 8$10 \mathrm{~mm}$.

It should be noted, that in our earlier studies only cellobiose lipid (2), 16-(tetra-O-acetyl-cellobiosyloxy)-2hydroxyhexadecanoic acid, was observed in the preparations obtained from $\mathrm{Cr}$. humicola ${ }^{16}$. However the fungicidal activity of such preparations was the same as in this study. So, we suggest, that the cellobiose lipid (2) possesses fungicide activity. Probably, the fungicidal activity of cellobiose lipid (1) is similar to that of cellobiose lipid (2) against test-cultures used.

So, the peculiarities of O-substituents in the cellobiose lipid of $P$ s. fusiformata are important for growth inhibition activity against mycelial fungi.

To assess the structural features of cellobiose lipids 1-3, which determine their fungicidal activity, fully O-deacylated analogues of compounds $1-3$, namely 16 - $(\beta$-cellobiosyloxy)-2,15-dihydroxyhexadecanoic acid (4) and 16-( $\beta$-cellobiosyloxy)-2-hydroxyhexadecanoic acid (5), were studied together with a totally synthetic compound 16 - $\beta$-cellobiosyloxy)-hexadecanoic acid (6). Compounds 4 and 5 were obtained from the glycolipid preparation of $\mathrm{Cr}$. humicola. With this purpose, the mixture of glycolipids was subjected to O-deacylation followed by esterification of carboxylic moiety and total O-acetylation. Derivatives 8 and 9 were easily isolated from the mixture of acetylated methyl esters by conventional silica gel column chromatography. Subsequent treatment of 8 and 9 with alkali yielded compounds 4 and 5. Glycosylation of methyl 16-hydroxyhexadecanoate with cellobiosyl trichloroacetimidate 10 gave $\beta$-glycoside 12 in moderate yield. Similar yields of $\beta$-glycosides were reported at glycosylation of methyl 16-hydroxyhexadecanoate with various glucosyl donors ${ }^{18}$. Saponification of the protected derivative 12 gave the target compound 6 .

Compound 6 with no OH-group and compound 5 with only one OH-group in the aglycon do not inhibit the growth of $F$. neoformans and $S$. cerevisiae, while compound $4 \mathrm{dou}^{-}$ ble-hydroxylated in the fatty acid moiety inhibits the growth of both test cultures but at higher amounts than glycolipid preparation from $\mathrm{Cr}$. humicola (Table 4). Amide 7 had no any activity against yeast species tested. It indicated the importance of terminal carboxyl group of fatty acid residue for fungicidal activity.

\section{CONCLUSION}

Thus, the structures of both the carbohydrate part and fatty acid aglycon moiety influence the fungicidal activity of cellobiose lipids under study. Their unique structure including $\mathrm{OH}$-groups in fatty acid residue and different $\mathrm{O}-$ substituents in cellobiose residue provides fungicidal activity. Taking into account the emergence of strains insensitive to known fungicides, cellobiose lipids are prospective for development of new antifungal compounds.

\section{ACKNOWLEDGEMENT}

This work was supported by the Russian Foundation for Basic Research (06-04-08253-ofi) and the Grant of support for the leading scientific schools of Russian Federation (NS-1004.2008.4.).

\section{References}

1. Spencer, J.F.T.; Spencer, D.M.; Tulloch, A.P. Extracellular glycolipids of yeasts. in Economic Microbiology, Secondary Products of Metabolism, 3, (Rose, A.H. ed.). Academic Press, London. pp. 523-540 (1979).

2. Kitamoto, D.; Isoda, Y.; Nakahara, T. Functions and potential applications of glycolipid biosurfactants from energy-saving material to gene delivery carriers. J. Biosci. Bioeng. 94, 87-201 (2002).

3. Cameotra, S.S.; Makkar, R.S. Recent applications of biosurfactants as biological and immunological molecules. Cur. Opin. Microbiol. 7, 262-266 (2004).

4. Fukuoka, T.; Morita, T.; Konishi, M.; Imura, T.; Kitamoto, D. Characterization of new types of mannosylerythritol lipids as biosurfactants produced from soybean oil by a basidiomycetous yeast, Pseudozyma shanxiensis. J. Oleo Sci. 56, 435-442 (2007).

5. Van Bogaert, I.N.A.; Saerens, K.; De Muynck, C.; Develter, D.; Soetaert, W.; Vandamme, E.J. Microbial production and application of sophorolipids. Appl. Microbiol. Biotechnol. 76, 23-34 (2007).

6. Rodrigues, L.; Banat, I.M.; Teixeira, J.; Oliveira, R. Biosurfactants: Potential application in medicine. $J$. Antimicrob. Chemother. 57, 609-618 (2007).

7. Muthusamy, K.; Gopalkrishnan, S.; Ravi, T.K.; Sivachidambaram, P. Biosurfactants: Properties, commercial production and application. Curr. Sci. 94, 736-747 (2008).

8. Lemieux, R.U.; Thorn, J.A.; Brice, C.; Haskins, R.H. Biochemistry of the ustilaginales. II. Isolation and partial characterization of ustilagic acid. Can. J. Chem. 29, 409-414 (1951).

9. Haskins, R.H.; Thorn, J.A. Biochemistry of the Ustilaginales. VII. Antibiotic activity of ustilagic acid. Can. J. Botany 29, 585-592 (1951).

10. Bhattacharjee, S.S.; Haskins, R.H.; Gorin, P.A.J. Location of acyl groups on two partly acylated glycolipids from strains of Ustilago (smut fungi). Carbohydr. Res. 13, 235-246 (1970). 
T. Kulakovskaya, A. Shashkov, E. Kulakovskaya et al.

11. Golubev, W.; Shabalin, Y. Microcin production in Cryptococcus humicola. FEMS Microbiol. Lett. 119, 105110 (1994).

12. Puchkov, E.O.; Zahringer, U.; Lindner, B.; Kulakovskaya, T.V.; Seydel, U.; Wiese, A. Mycocidal, membrane-active complex of Cryptococcus humicola is a new type of cellobiose lipid with detergent features. Biochim. Biophys. Acta (Biomembranes) 1558, 161-170 (2002).

13. Kulakovskaya, T.V.; Shashkov, A.S.; Kulakovskaya, E.V.; Golubev, W.I. Ustilagig acid secretion by Pseudozyma fusiformata strains. FEMS Yeast Res. 5, 919-923 (2005).

14. Cheng, Y.; McNally, D.J.; Labbe, C.; Voyer, N; Belzyle, F.; Belanger, RR. Insertional mutagenesis of a fungal biocontrol agent led to a discovery of a rare cellobiose lipid with antifungal activity. Appl. Environ. Microbiol. 69, 2595-2602 (2003).

15. Mimee, B.; Labbe, C.; Pelletier, R.; Belanger, RR. Antifungal activity of flocculosin, a novel glycolipid isolated from Pseudozyma flocculosa. Antimicrob. Agents Chemother. 49, 1597-1599 (2005).
16. Kulakovskaya, E.V.; Golubev, V.I.; Kulaev, I.S. Extracellular antifungal glycolipids of Cryptococcus humicola yeasts. Dokl. Biol. Sci. 410, 393-395 (2006).

17. Kulakovskaya, E.V.; Kulakovskaya, T.V.; Golubev, W.I.; Shashkov, A.S.; Grachev, A.A.; Nifantiev, N.E. Fungicidal activity of cellobiose lipids from culture broth of yeast Cryptococcus humicola and Pseudozyma fusiformata. Russian J. Bioorg. Chem. 33, 156-161 (2007).

18. Gouin, S.G.; Pilgrim, W.; Porterb, R.K.; Murphy, P.V. Synthesis of a glycolipid for studying mechanisms of mitochondrial uncoupling proteins. Carbohydr. Res. 340, 1547-1552 (2005).

19. Chang, C.W.T.; Hui, Y.; Elchert, B.; Wang, J,; Li, J.; Rai, R. Pyranmycins, a novel class of aminoglycosides with improved acid stability: the SAR of D-pyranoses on ring III of pyranmycin. Org. Lett. 4, 4603-4606 (2002).

20. Waugh, K.M.; Berlin, K.D. Studies in lipid mimics. Synthesis and carbon-13 relaxation time measurements (T[1] values) of methyl esters of $\omega$-(2-anthryl)alkanoic acids. J. Org. Chem. 49, 873-878 (1984). 